\title{
Structural and Pragmatic Language Impairments in Children Evaluated for Autism Spectrum Disorder (ASD)
}

\author{
Lise Reindal ${ }^{1,2} \odot$ Terje Nærland ${ }^{3,4} \cdot$ Bernhard Weidle $^{2,5} \cdot$ Stian Lydersen $^{2} \cdot$ Ole A. Andreassen ${ }^{4,6,7} \cdot$ Anne Mari Sund $^{2,5}$
}

Accepted: 16 December 2020 / Published online: 30 January 2021

(c) The Author(s) 2021

\begin{abstract}
Pragmatic language impairments are common in neurodevelopmental disorders, especially in autism spectrum disorder (ASD). The relationship between structural language skills and pragmatic competence in children with autistic symptoms, however, is largely unknown. We investigated this relationship based on the Children's Communication Checklist-2 and early language delay among children ( $N=177,19 \%$ females) clinically evaluated for ASD, differentiated into ASD $(n=148)$ and non-ASD $(n=29)$. Structural language deficits were common and associated with reduced pragmatic competence in both groups. Pragmatic language impairments were most profound in children with ASD. Early language delay and structural language deficits were less common in females. Our findings suggest that assessment of structural language skills should be included in the evaluation of children with suspected ASD.
\end{abstract}

Keywords Autism spectrum disorder · Language impairment · Structural language skills · Pragmatic language skills · Language milestones $\cdot$ Sex differences

\section{Introduction}

Neurodevelopmental disorders (NDDs) are characterized by impairments in one or more developmental domains, such as cognition, communication, social, and motor functioning, as a result of atypical brain development (American Psychiatric Association 2013; Moreno-De-Luca et al.

\section{Lise Reindal}

lise.reindal@ntnu.no

1 Department of Child and Adolescent Psychiatry, Møre og Romsdal Hospital Trust, Volda Hospital, Volda, Norway

2 Department of Mental Health, Faculty of Medicine and Health Sciences, Regional Centre for Child and Youth Mental Health and Child Welfare, Norwegian University of Science and Technology, Trondheim, Norway

3 NevSom, Department of Rare Disorders and Disabilities, Oslo University Hospital, Oslo, Norway

4 K.G Jebsen Centre for Neurodevelopmental Disorders, University of Oslo, Oslo, Norway

5 Department of Child and Adolescent Psychiatry, St. Olavs University Hospital, Trondheim, Norway

6 NORMENT Centre, University of Oslo, Oslo, Norway

7 Division of Mental Health and Addiction, Oslo University Hospital, Oslo, Norway
2013). Autism spectrum disorder (ASD) is a childhood onset NDD characterized by persistent deficits in social communication and interaction, as well as restricted, repetitive behavior and interests (American Psychiatric Association 2013; World Health Organization 1992). The common cooccurrence of different NDDs and the dimensional nature of their symptom profiles represent major challenges to the recognition, as well as the classification of these disorders (Baird and Norbury 2016). Many children with NDDs have language difficulties, particularly using language in social communication. In a clinical setting, however, language impairments are often unnoticed due to other, more prominent symptoms, and frequently remain undiagnosed (Cohen et al. 1998). Although a neglected area in current research, language impairment is suggested as an associated feature, independent from core ASD features in some aspects, with great importance for outcome in individuals on the autism spectrum (Happé and Frith 2020).

Within communication the form, content and use of language are all essential components. Language form (e.g. phonology, morphology, syntax) and content (semantics) represent structural language skills, while appropriate use of language in social or situational contexts represent pragmatic language skills (e.g. Geurts and Embrechts 2008; Baird and Norbury 2016). Language impairments reflect 
deficits in one or more of these skills, and vary depending on the individual's age, intellectual level, as well as cooccurring difficulties in other developmental domains (Lord et al. 2018; Boucher 2012).

Impairments in pragmatic language are observed in a broad range of NDDs, including ASD (e.g. Bishop 1998; Norbury et al. 2004; Gilmour et al. 2004; Geurts and Embrechts 2008). Although not required for meeting diagnostic criteria, pragmatic impairments are a recognized feature of ASD regardless of language level or age (e.g., Baird and Norbury 2016; La Valle et al. 2020). Still, these impairments are often less emphasized than the social communication impairments inherent in the ASD diagnosis (Norbury 2014). Pragmatic skills require use of both the language and the social context to reach intended meaning. As such, they stand at the intersection of structural language and social skills (Volden et al. 2009). Norbury (2014) has argued that pragmatic language skills are closely associated with structural aspects of language, and not necessarily the same as social communication skills.

Although receiving less attention than pragmatic language deficits, structural language is also commonly affected in ASD. Preschool children with ASD show structural as well as pragmatic language impairments, resembling the language profile in children with specific language impairment (Geurts and Embrechts 2008; Boucher 2012). By school-age, however, structural deficits are reported to improve, while pragmatic language deficits become more prominent (Rapin and Dunn 2003; Geurts and Embrechts 2008). Moreover, an ASD-typical profile is reported to emerge in school-age, with articulation and syntax least affected, and comprehension, semantics and morphology most affected, as reviewed by Boucher (2012). Notably, children with ASD often evidence variability in skills across specific language domains, which appear to differentially relate to other aspects of functioning (Levinson et al. 2020). While previous work is limited and has disproportionately focused on the association between pragmatic language and social skill deficits, there are reports suggesting a link between structural language deficits and social skills in ASD, that is mediated by reduced pragmatic competence and may be at play for children without ASD as well (Volden et al. 2009; Levinson et al. 2020). Concomitant deficits in structural language may represent a potential target of intervention, separate from the social communication impairments characteristic of ASD. Therefore, investigating structural language skills and their potential influence on pragmatic competence in referred children with autistic symptoms is of importance.

ASD symptoms vary widely across individuals meeting diagnostic criteria for ASD and are also present in the general population to a minor degree (Constantino and Todd 2003, 2005; Posserud et al. 2006). For clinicians evaluating children with autistic symptoms, it may be challenging to disentangle core ASD symptoms from more specific language impairments that disturb social communication (Levy et al. 2010; Baird and Norbury 2016). It has been argued that the association between the different disorders affecting language and communication may best be understood dimensionally (Bishop and Norbury 2002; Bishop 2000). The individual differences in social communication and pragmatic language seen across various NDDs may then reflect a confluence of risk factors such as deficits in structural language, social and cognitive skills, with ASD at "the extreme end of the distribution" (Norbury 2014, p. 212), but without a disorder-specific profile. Investigating language impairments in a broader clinical population of children with autistic symptoms, beyond those receiving an ASD diagnosis, can offer an important complementary insight into the nature of these impairments and their extent in both ASD and non-ASD individuals.

The Children's Communication Checklist (CCC-2) (Bishop 2011, 2003) is designed to identify structural and pragmatic language deficits that may be difficult to elicit in a test situation, and is to be completed by an adult who knows the child well (Norbury et al. 2004). Previous efforts to distinguish different NDDs based on their CCC-2 language profile have largely failed, but significant deficits in structural language in children with ASD compared to typically developing children are documented (Kuijper et al. 2017; Baixauli-Fortea et al. 2019; Geurts and Embrechts 2008). In addition pragmatic language impairments were evident in children across a range of NDDs, many of them had structural language deficits as well (Norbury et al. 2004; Geurts and Embrechts 2008). Recently, Baixauli-Fortea et al. (2019) reported an association between more advanced structural language skills and greater pragmatic competence in children with ASD, as measured by the CCC-2. On a continuum of communication impairment, ASD and specific language impairment are found on the opposite endpoints, with comparable structural language skills but more profound pragmatic impairments in children with ASD (Oi et al. 2017). However, design, measures, and comparison groups varied between these studies, limiting comparability and generalization of their results. Further, the ASD groups in many of these studies were relatively small. Thus, an unanswered question is whether pragmatic language impairment represents a dimensional trait that is associated with structural language deficits across the range of autistic symptoms.

While language milestones and current language skills have been important for distinction between ASD subtypes (e.g. World Health Organization 1992), they are not found to predict autistic symptom severity in children with ASD (Loucas et al. 2008; Kenworthy et al. 2012). Still, lasting individual differences in language skills seem to be established early, underscoring the importance of identifying lagging language skills early in life (Bornstein et al. 2018). 
Being a "late talker" (i.e. delayed attainment of first words and/or first word combinations) is considered a hallmark of specific language impairment (Conti-Ramsden and Durkin 2015), a condition characterized by structural language deficits. Delays in language milestones are also common in children later diagnosed with ASD, and represent early signs of the condition, although with low specificity (Tager-Flusberg 2016). Measured by a sentence repetition task, retrospectively reported language milestones were predictive of later structural language skills in children with ASD (Kenworthy et al. 2012). Whether milestone data can be useful markers of later language performance also across the broader range of autistic symptoms, as measured by the CCC-2, remains to be resolved.

Females demonstrated better pragmatic language skills on the CCC (Ketelaars et al. 2010; Geurts et al. 2009) and its successor, the CCC-2 (Ash et al. 2017) in communitybased samples. However, no significant sex differences were found in a Norwegian normative sample (HollundMøllerhaug 2010). Regarding ASD, females may present with a different profile of symptoms than males, and therefore be under- or misdiagnosed, or diagnosed with delay (Green et al. 2019; Kreiser and White 2014; Van Wijngaarden-Cremers et al. 2014). At present, studies exploring potential sex differences in language characteristics within the broader group of children with autistic symptoms are lacking.

While originally autism was conceptualized as distinct from typical development, a more recent conception is the dimensional, with ASD as a spectrum of manifestations and no natural cut-off point between high autism traits and ASD (Happé and Frith 2020). The same authors argue that an unintended consequence of focusing on 'pure' autism has been the neglect of language impairment in recent research (Happé and Frith 2020). By including a large group of children evaluated for ASD by specialist health services, some not fulfilling the criteria for such a diagnosis (non-ASD), we aimed to use a dimensional approach and study language impairment across the broader range of autistic symptoms. Four specific objectives were addressed:

(i) To investigate the extent of language deficits based on the CCC-2 (composite and subscale scores) and parents retrospective report of early language delay.

(ii) To investigate whether current structural language skills are associated with pragmatic competence (as measured by CCC- 2 composite scores).

(iii) To explore whether parent reported early language delay predict current language and social skills as measured by CCC- 2 composite scores and Social Responsiveness Scale (SRS) total score.

(iv) To explore potential sex differences in language characteristics.

\section{Methods}

\section{Study Design}

The present study is part of BUPgen, an ongoing large multi-site study of neurodevelopmental disorders in Norway, in which children are eligible for enrollment if a suspicion of ASD has been raised by local or specialist health services. This study involved analyses of data collected and processed by April 2019. Data are collected from two types of sites: (1) child habilitation services and (2) child and adolescent mental health services, i.e. public specialist health services receiving referrals for assessment of ASD. After written, informed consent to participate, information from patients' records was extracted by clinicians, following standard procedures.

\section{Participants}

Participants were eligible if information on age (4-18 years) at inclusion, diagnostic classification as either ASD or non-ASD, and results from assessment with the Children's Communication Checklist Second Edition (CCC-2) was available. In total, $N=177$ children were included, born between 1994 and 2012, with a mean age at inclusion of 12.3 years (standard deviation $(S D)=3.3$ ). As the CCC-2 is only completed when the child can speak in at least simple sentences, all participants were verbal. Children were not excluded from participation if they were bilingual speakers of Norwegian $(n=6)$, if they had histories of impaired hearing $(n=14)$ or receiving services from a speech therapist $(n=21)$. Data included results from present and previous clinical assessments, parent-reported history and supplementary parent-reported measures.

Participants consisted of 148 children (83.6\%) with a clinical diagnosis of any ASD according to ICD-10 (F84x) and 29 children (16.4\%) with suspected ASD, but no clinical ASD diagnosis (non-ASD). Common ASD subtypes included Asperger syndrome (AS) (80/148, 54.1\%), Pervasive developmental disorder not otherwise specified (45/148, $30.4 \%)$, Childhood autism (14/148, 9.5\%) and Atypical autism $(7 / 148,4.7 \%)$, whereas the majority of non-ASD children had one or more NDDs $(21 / 26,80.8 \%)$. Other NDDs were grouped according to ICD-10 codes into the following categories: intellectual disability (F70-79), attention-deficit/ hyperactivity disorder (ADHD) (F90), communication disorder (F80), specific learning disorder (F81 and F83), motor disorder (F82 and F95), other NDD (F88, F89 and F94). The presence of epilepsy or cerebral palsy was also registered and included in the total number of NDDs. 


\section{Assessments}

\section{Diagnoses}

All diagnoses were assigned by Norwegian specialist health services, using the International Statistical Classification of Diseases, 10th Revision (ICD-10) criteria (World Health Organization 1992). The majority of ASD (121/148, 81.8\%) and non-ASD individuals $(20 / 28,71.4 \%)$ had completed the Autism Diagnostic Observation Schedule (ADOS) (Lord et al. 1999), or the Autism Diagnostic Interview-Revised (ADI-R) (Rutter et al. 2003b), or both as part of the clinical evaluation. In cases where ADI-R had not been administered, the Social Communication Questionnaire (SCQ), Lifetime form (Rutter et al. 2003a) was completed at inclusion-if not performed earlier.

\section{Early Language Development}

A clinician rated medical history form was obtained for all participants at inclusion, which inquired whether the child had attained one spoken word at 1 years' age, and whether the child had attained its first phrase (a spoken two-word combination) at 2 years' age. This assessment was completed based on the child's medical record supplemented by parent report, asking parents to retrospectively recall this information. Among children with ASD and normal range cognitive abilities, Kenworthy et al. (2012) found attainment of first phrase speech by 2 years' ( 24 months) age to be a useful marker for distinguishing later language trajectories. For simplicity, therefore, not having attained first phrase at 2 years' age was used as a proxy for early language delay in the present study.

\section{Current Language and Communication Skills}

The Children's Communication Checklist Second Edition (CCC-2) (Bishop 2003; Norwegian version: Bishop 2011) is a caregiver reported measure that identifies children with language impairment in both clinical (Norbury et al. 2004) and community contexts (Ketelaars et al. 2009). The CCC-2 consists of 70 items grouped into 10 subscales that measure different aspects of communication: language structure (A: speech, B: syntax, C: semantics, D: coherence), pragmatic language skills (E: inappropriate initiation, $F$ : stereotyped language, G: use of context, H: nonverbal communication), and two scales measuring social aspects (I: social relations and $\mathrm{J}$ : interests). The raw scores are converted into scaled scores with a mean of 10 and an SD of 3 based on Norwegian norms, that can also be converted into percentiles for each subscale. The Norwegian version of the CCC-2 has satisfactory internal consistency (Cronbach alpha ranging from 0.73 to 0.89 ) and inter-rater reliability (Spearman's rho ranging from 0.44 to 0.76 ) (Helland et al. 2009). The checklist does not provide a categorical diagnosis, but subscales may be combined as composites. The General Communication Composite (GCC) is an overall measure of communication skills, derived by adding the scaled scores of the subscales A-H. In scaled scores a high score indicates language strength and a low score language deficit. A GCC below 55 is considered the cut-off for distinguishing children with clinically significant language impairment from typically developing (TD) children (Bishop 2011). We calculated the Structural Language Score, obtained by adding together the scores on the structural scales (A-D) and the General Pragmatics Score by adding together the scores on the four pragmatic scales $(\mathrm{E}-\mathrm{H})$, without the two social nonlinguistic scales (I, J). This specific grouping has been used in other studies (Baixauli-Fortea et al. 2019; Kuijper et al. 2017). Contrary to these, we report scaled scores (see Appendix for further discussion).

\section{Current Social Impairment}

The Social Responsiveness Scale (SRS) (Constantino and Gruber 2005) is a 65-item caregiver questionnaire that examines a child's ability to engage in reciprocal social interaction. The SRS total score is a valid quantitative measure of autistic social impairment or traits, with higher scores indicating greater severity (Constantino et al. 2003). Previous reports indicate excellent internal consistency of the SRS, with a Cronbach alpha coefficient of .97 (Constantino and Gruber 2005). In the present study, we applied SRS raw total as a dimensional trait variable reflecting current (last 6 months) level of social impairment.

\section{Cognitive Abilities}

Cognitive function was assessed using results from ageappropriate Wechsler scales $(n=169)$ : the Wechsler Preschool and Primary Scale of Intelligence (Wechsler 2012; $12.4 \%$ ), Wechsler Intelligence Scale for Children (Wechsler 2003; 81.7\%), Wechsler Abbreviated Scale of Intelligence (Wechsler 1999; 3.0\%), and Wechsler Adult Intelligence Scale (Wechsler 2008; 3.0\%). These assessments yield standard scores for nonverbal IQ (NVIQ), verbal IQ, and full-scale IQ. Mean age at assessment of cognitive abilities in the present sample $(n=168)$ was $10.0(S D=3.4)$ years. To minimize the effect of language in measuring cognitive abilities, we used NVIQ as a trait variable, reflecting severity of cognitive impairment.

\section{Statistical Analyses}

Descriptive statistics are presented as $n(\%)$ and mean $(S D)$. First, we report the extent of language deficits by the mean 
(SD) for the CCC- 2 composite and subscale scores. We also assessed the proportion of children with scores below the chosen cut-off to indicate significant deficits (i.e. GCC $<55$ or subscale score $\leq 5$ th percentile compared to the Norwegian norms, respectively). Second, we investigated whether current structural language skills were associated with pragmatic competence across the whole sample by performing a linear regression analysis with the General Pragmatics Score as dependent variable. The analysis was carried out unadjusted and adjusted for potential confounders, one at a time, and simultaneously. Potential confounding factors included were NVIQ, age at inclusion, and sex. Third, we divided the sample into two groups based on early language delay (i.e. not having attained first phrase at 2 years' age) and compared current language and social skills between these groups. We used independent sample $t$-test and Pearson's chi-squared for between-group comparisons. Mean CCC-2 composite scores were compared using linear regression, adjusting for cognitive ability (NVIQ) and age at inclusion (years). To compare proportions, we computed the Newcombe hybrid score confidence interval as recommended by Fagerland et al. (2015) using Stata 16, and the unconditional z-pooled test as recommended by Lydersen et al. (2012) using StatXact 11. Finally, to explore possible sex differences, group comparisons were repeated for males and females within the whole sample. Possible sex differences in the association between structural and pragmatic language skills were explored in a subsequent regression analysis including an interaction term between sex and the Structural Language Score.

We report available case analyses with the corresponding number of missing cases where appropriate. Following the example of Geurts and Embrechts (2008) we conducted these analyses with $(n=177)$ and without $(n=153)$ the inclusion of participants with invalid consistency check on the CCC-2. As the results in general were the same, the values in tables and figures include all children $(n=177)$. Two-sided $p$ values $<0.05$ were regarded as statistically significant. In order to protect against type I error due to multiple hypotheses, however, we recommend $p$-values between .01 and .05 to be interpreted with caution. Except otherwise noted, we used SPSS 26 for statistical analyses.

\section{Results}

\section{Sample Characteristics}

The main sample $(N=177)$ included 143 males $(80.8 \%)$ with a male to female ratio of approximately $4: 1$ (Table 1). Most children (148/177, 83.6\%) had an ASD diagnosis. The majority of children that did not meet the criteria for an ASD diagnosis (non-ASD) were diagnosed with one or more NDDs, mainly ADHD (17/27, 63.0\%), specific learning
Table 1 Participant characteristics $(N=177)$

\begin{tabular}{|c|c|c|c|c|}
\hline & $n$ & $(\%)$ & Range & Mean (SD) \\
\hline Male sex & 143 & 80.8 & & \\
\hline Age (years) at inclusion & 177 & & $4-18$ & $12.3(3.3)$ \\
\hline Age (years) at ASD diagnosis & 144 & & & $11.5(3.3)$ \\
\hline $\begin{array}{l}\text { Current social impairment (SRS } \\
\text { total) }\end{array}$ & 162 & & $9-153$ & $83.4(29.8)$ \\
\hline Age (years) at cognitive testing & 168 & & $4-18$ & $10.0(3.4)$ \\
\hline Nonverbal IQ & 161 & & $59-142$ & $102.5(18.4)$ \\
\hline Verbal IQ & 163 & & $53-124$ & $91.4(16.9)$ \\
\hline \multicolumn{5}{|l|}{ Early language milestones } \\
\hline One word 1 year (no) & 32 & 22.2 & & \\
\hline Two words 2 year (no) & 38 & 27.1 & & \\
\hline \multicolumn{5}{|l|}{ Diagnoses } \\
\hline $\operatorname{ASD}(\mathrm{F} 84)$ & 148 & 83.6 & & \\
\hline Intellectual Disability (F70-79) & 8 & 4.6 & & \\
\hline ADHD (F90) & 103 & 59.9 & & \\
\hline Communication disorder (F80) & 7 & 4.1 & & \\
\hline $\begin{array}{l}\text { Specific learning disorder } \\
(\mathrm{F} 81+\mathrm{F} 83)\end{array}$ & 18 & 10.5 & & \\
\hline Motor disorders (F82 + F95) & 27 & 15.7 & & \\
\hline Epilepsy & 10 & 5.6 & & \\
\hline Cerebral Palsy & 2 & 1.1 & & \\
\hline Other NDD (F94) & 1 & 0.6 & & \\
\hline \multicolumn{5}{|l|}{ No of NDDs } \\
\hline 0 & 5 & 2.8 & & \\
\hline 1 & 58 & 32.8 & & \\
\hline$\geq 2$ & 106 & 59.9 & & \\
\hline \multicolumn{5}{|l|}{ Ethnicity } \\
\hline European (Caucasian) & 157 & 88.7 & & \\
\hline
\end{tabular}

Data are expressed as $n(\%)$ or mean (SD). The denominator for the reported proportions in this table excludes those with missing data. IQ was obtained from various age-appropriate standardized tests

$A S D$ autism spectrum disorder, SRS Social Responsiveness Scale, $N D D$ neurodevelopmental disorder

disorders $(6 / 27,22.2 \%)$, and motor disorders $(5 / 27,18.5 \%)$. Co-occurrent ADHD was equally frequent among children with ASD (86/145, 59.3\%) and did not differ between groups. Within the whole sample, participating females $(n=34)$ were older at inclusion compared with males (13.5 $(S D=3.2)$ versus $12.0(S D=3.3)$ years $)$, and females with ASD had received their diagnosis later $(13.6(S D=2.8)$ versus $11.0(S D=3.3)$ years among ASD males).

Mean age at ASD diagnosis was 11.5 years $(S D=3.3)$. Children with ASD had higher mean scores on diagnostic measures as well as the measure of current social skills (SRS) compared with non-ASD $(p<.01$, all). Non-ASD individuals were younger at inclusion (11.0 years $(S D=3.7)$ versus 12.5 years $(S D=3.2)$ in the ASD group). Mean age at assessment of cognitive abilities and at administration of ADI-R, however, did not differ between the groups. Lastly, 
mean values of nonverbal and verbal cognitive abilities were in the normal range and without significant group differences (see Appendix for details on characteristics in both groups).

\section{Extent of Language Deficits Across the Range of Autistic Symptoms}

Most children (144/177, 81\%) were classified as language impaired, by the CCC-2 (GCC < 55) (Table 2). In general, pragmatic language deficits were more common than structural deficits. Among the structural language skills, 'syntax' was least affected. Still, $27 \%$ of children had significant deficits on this subscale ( $\leq 5$ th percentile). Moreover, $66 \%$ had significant deficits on the 'coherence' subscale, which was the most affected structural scale. For all subscales measuring pragmatic aspects of language, more than half of the sample presented with significant deficits. The most affected pragmatic skill in both groups was nonverbal communication. However, in children with ASD, the deficits on the 'nonverbal communication' subscale were more profound $(4.2(S D=2.7))$ than in the non-ASD group $(5.6(S D=2.9)$; $p=.01)$. The ASD group also performed worse on the General Pragmatics Score compared to the non-ASD group $(16.3(S D=9.2)$ versus $21.1(S D=11.3) ; p=.01)$. Both groups performed equally on the GCC and the Structural Language Score. Adjusting for NVIQ and age at inclusion did not alter these findings substantially. Notably, language impairment was not universal. Within the whole sample, 33 children (19\%) did not have any language impairment as measured by the CCC-2. A minority $(38 / 140,27 \%)$ had reported early language delay, i.e. not having attained first phrase at 2 years' age (Table 1). Analyses comparing characteristics between individuals with $(n=153)$ and without $(n=22)$ valid consistency check on the CCC- 2 are presented in the Appendix.

\section{The Relationship Between Current Structural Language Skills and Pragmatic Competence}

The Structural Language Score was strongly associated with the General Pragmatics Score with a regression coefficient 0.56 (CI 0.45 to 0.68 ), $p<.001$, and explained $35.9 \%$ of the variance in the General Pragmatics Score. After adjustment for potentially confounding variables, the association remained substantially unchanged (Table 3 ). The potential influence of diagnostic group on the observed association was also explored. As illustrated in Fig. 1, current structural and pragmatic language skills, as measured by the CCC-2, were highly correlated regardless of diagnostic group.

Table 2 CCC-2 subscale and composite scores (a high score indicates better language ability): means, standard deviations, proportion below 'cut-off' indicating significant deficits for the whole sample, the ASD and the non-ASD group

\begin{tabular}{|c|c|c|c|c|c|c|c|c|c|}
\hline & \multicolumn{3}{|c|}{ Whole sample } & \multicolumn{3}{|l|}{ ASD } & \multicolumn{3}{|c|}{ Non-ASD } \\
\hline & \multicolumn{3}{|c|}{$N=177$} & \multicolumn{3}{|c|}{$n=148$} & \multicolumn{3}{|l|}{$n=29$} \\
\hline & Mean & SD & Below 'cut-off' (\%) & Mean & SD & Below 'cut-off' (\%) & Mean & SD & Below 'cut-off' (\%) \\
\hline CCC-2 subscale scores & & & $\leq 5$ percentile* & & & $\leq 5$ percentile* & & & $\leq 5$ percentile* \\
\hline A. Speech & 6.5 & 3.9 & 35.0 & 6.6 & 4.0 & 35.1 & 5.9 & 3.6 & 34.5 \\
\hline B. Syntax & 6.5 & 3.6 & 27.1 & 6.6 & 3.6 & 27.0 & 6.4 & 3.6 & 27.6 \\
\hline C. Semantics & 5.0 & 3.1 & 34.5 & 4.8 & 3.0 & 35.8 & 5.9 & 3.4 & 27.6 \\
\hline D. Coherence & 4.0 & 3.0 & 66.1 & 3.9 & 2.9 & 67.6 & 4.7 & 3.5 & 58.6 \\
\hline E. Inappropriate initiation & 4.5 & 2.6 & 55.4 & 4.3 & 2.4 & 58.1 & 5.6 & 3.2 & 41.3 \\
\hline F. Stereotyped language & 4.8 & 3.0 & 50.8 & 4.6 & 3.0 & 52.0 & 5.7 & 3.0 & 44.8 \\
\hline G. Use of context & 3.4 & 3.0 & 57.1 & 3.2 & 2.9 & 60.1 & 4.3 & 3.4 & 41.4 \\
\hline H. Nonverbal communication & 4.4 & 2.8 & 71.8 & 4.2 & 2.7 & 75.7 & 5.6 & 2.9 & 51.7 \\
\hline I. Social relations & 3.3 & 2.9 & 73.4 & 3.0 & 2.6 & 77.7 & 5.1 & 3.6 & 51.7 \\
\hline J. Interests & 3.3 & 2.3 & 60.5 & 3.1 & 2.2 & 66.2 & 4.7 & 2.5 & 31.0 \\
\hline CCC-2 composite scores & & & $\mathrm{GCC}<55$ & & & $\mathrm{GCC}<55$ & & & $\mathrm{GCC}<55$ \\
\hline $\begin{array}{l}\text { GCC } \\
\text { (sum scales A-H) }\end{array}$ & 39.1 & 17.9 & 81.4 & 38.1 & 17.2 & 83.8 & 44.2 & 20.9 & 69.0 \\
\hline $\begin{array}{l}\text { Structural Language Score } \\
\text { (sum scales A-D) }\end{array}$ & 22.0 & 10.3 & n.a & 21.8 & 10.0 & n.a & 22.9 & 11.9 & n.a \\
\hline $\begin{array}{l}\text { General Pragmatics Score } \\
\text { (sum scales E-H) }\end{array}$ & 17.1 & 9.7 & n.a & 16.3 & 9.2 & n.a & 21.1 & 11.3 & n.a \\
\hline
\end{tabular}

$A S D$ autism spectrum disorder, $C C C$-2 Children's Communication Checklist Second Edition, $S D$ standard deviation, n.a. not applicable

*Proportion (\%) of individuals with subscale score at or below the 5 th percentile compared to Norwegian norms 
Table 3 Linear regression with General Pragmatics Score as dependent variable and Structural Language Score as primary covariate (scaled scores)

\begin{tabular}{lcccc}
\hline & \multicolumn{3}{l}{ Correlation coefficient } & \multirow{2}{*}{$p$} \\
\cline { 2 - 4 } & $n$ & $\mathrm{~B}$ & $95 \% \mathrm{CI}$ & \\
\hline $\begin{array}{l}\text { Unadjusted } \\
\text { Structural Language Score }\end{array}$ & 177 & .56 & $(.45$ to .68$)$ & $<.001$ \\
$\begin{array}{l}\text { Adjusted separately for } \\
\text { Sex (female) }\end{array}$ & 177 & .57 & $(.45$ to .68$)$ & $<.001$ \\
Age (years) & 177 & .57 & $(.46$ to .68$)$ & $<.001$ \\
Nonverbal IQ & 161 & .60 & $(.48$ to .72$)$ & $<.001$ \\
Adjusted for all & 161 & .60 & $(.48$ to .72$)$ & $<.001$ \\
\hline
\end{tabular}

Results based on available case analysis of the main sample

$B$ unstandardized regression coefficient, $C I$ confidence interval, $p$ $p$-value

\section{Early Language Delay and Current Language and Social Skills}

Within the whole sample, the 38 children with reported language delay performed worse on current measures of general communication (GCC; $34.1(S D=18.8)$ versus $40.9(S D=16.8) ; p=.04)$ and structural language skills (Structural Language Score; $17.0(\mathrm{SD}=10.4)$ versus 23.9
$(\mathrm{SD}=9.5) ; p<.001)$ compared with the 102 children without language delay. No significant difference was found regarding pragmatic skills (Fig. 2). Adjusting for NVIQ and age at inclusion did not alter the findings substantially, except that the difference in GCC no longer was significant $(p=.20)$. Children in the language delayed group also performed worse on measures of verbal IQ $(80.8(S D=16.2)$ versus $94.9(S D=15.1)$, respectively; $p<.001)$, while no difference was found regarding current social skills (SRS total raw score), when compared with the group without language delay. Children receiving an ASD diagnosis were diagnosed earlier if they had early language delay (10.1 years $(S D=4.0)$ versus 11.9 years $(S D=2.9) ; p=.03)$.

\section{Sex Differences}

The majority of both males $(117 / 143,82 \%)$ and females $(27 / 34,79 \%)$ was identified as language impaired $(\mathrm{GCC}<55)$, and the overall extent and profile of language impairments, as measured by the CCC- 2 composite scores, did not differ by sex (unadjusted and adjusted for potential confounders) (Table 4). Generally, females had higher mean scores (indicating better performance) on most subscales, although reaching statistical significance only for the 'syntax' subscale ( $p=.02)$ (Fig. 3). There was no significant interaction between sex and Structural Language Score on

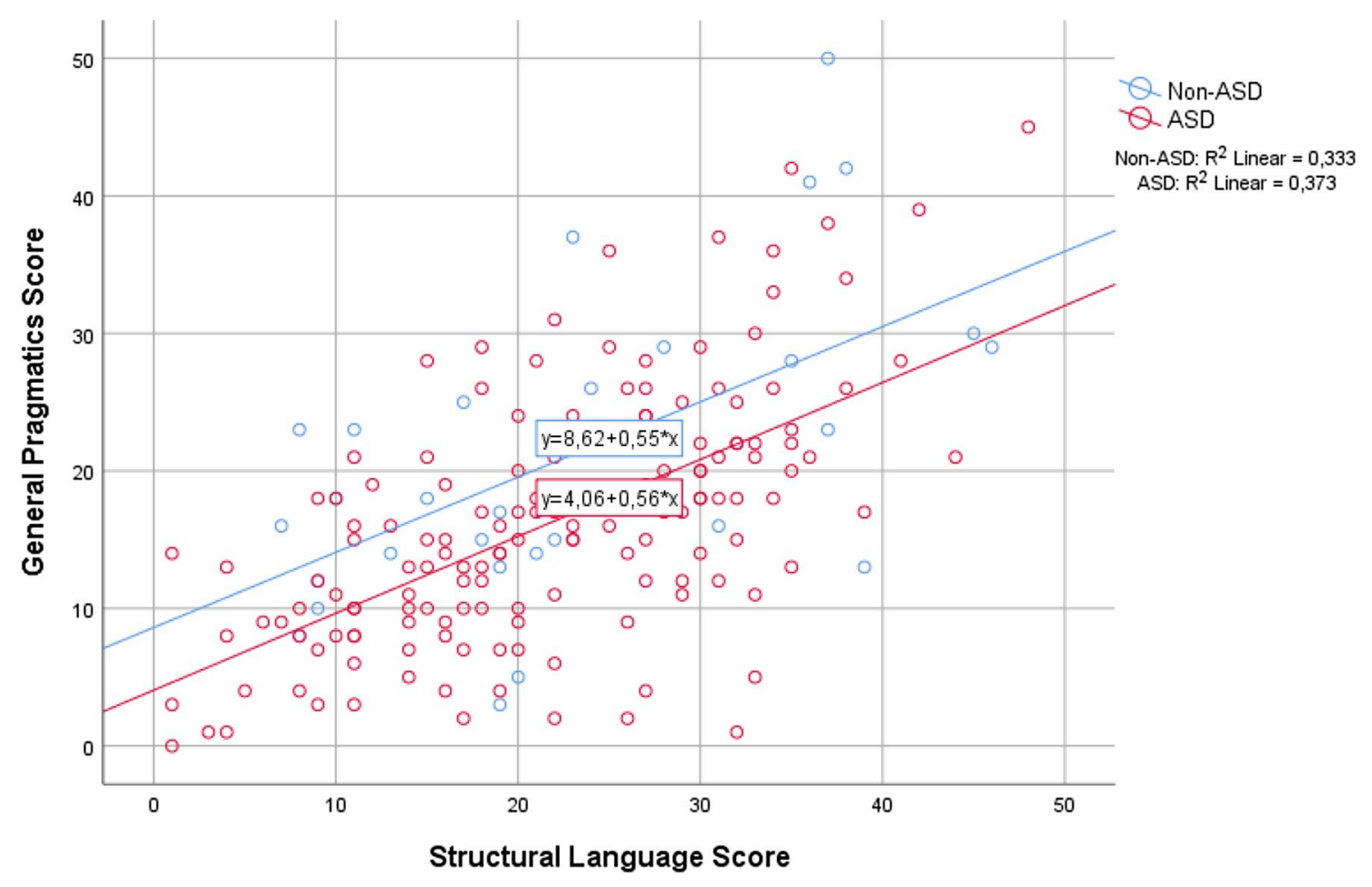

Fig. 1 Distribution of Structural Language and General Pragmatics composite scores across the study sample $(N=177)$, and their linear associations in the group with and without diagnosed autism spectrum disorder (ASD; $n=148$ and non-ASD; $n=29$ ) 


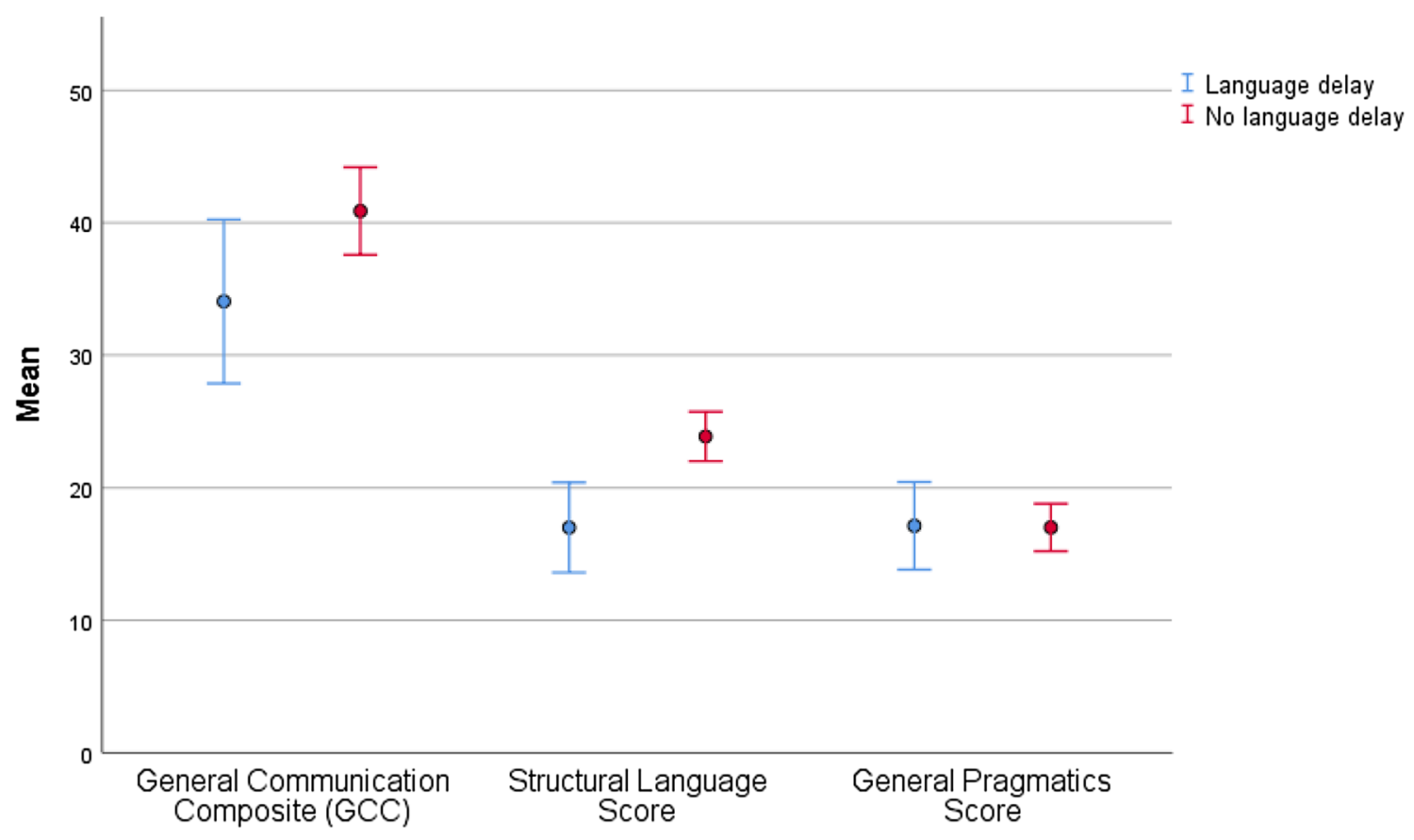

Error Bars: $95 \% \mathrm{Cl}$

Fig. 2 Clustered error bar mean of CCC-2 composite scores of children $(n=140)$ with parent report on early language delay, separated into children with $(n=38)$ and without $(n=102)$ early language delay (i.e. not having attained first phrase at 2 years' age). Means and $95 \%$ CI

Table 4 Participant and language characteristics by sex $(N=177)$

\begin{tabular}{|c|c|c|c|c|c|c|c|c|c|}
\hline & \multicolumn{3}{|c|}{ Males $(n=143)$} & \multicolumn{3}{|c|}{ Females $(n=34)$} & \multicolumn{3}{|c|}{ Difference } \\
\hline & $n$ & $(\%)$ & Mean (SD) & $n$ & $(\%)$ & Mean (SD) & Estimate & $95 \% \mathrm{CI}$ & $p$ \\
\hline ASD & 119 & 83.2 & & 29 & 85.3 & & -2.1 & $(-12.9$ to 14.2$)$ & .79 \\
\hline Age (years) at inclusion & 143 & & $12.0(3.3)$ & 34 & & $13.5(3.2)$ & -1.5 & $(-2.8$ to -.3$)$ & .02 \\
\hline Age (years) at ASD diagnosis & 118 & & $11.0(3.2)$ & 26 & & $13.6(2.8)$ & -2.6 & $(-4.0$ to -1.2$)$ & $<.001$ \\
\hline Age (years) at cognitive testing & 135 & & $9.8(3.4)$ & 33 & & $10.9(3.2)$ & -1.1 & $(-2.4$ to .15$)$ & .08 \\
\hline Nonverbal IQ & 128 & & $102.7(19.6)$ & 33 & & $101.8(12.9)$ & 1.0 & $(-4.7$ to 6.6$)$ & .74 \\
\hline Verbal IQ & 130 & & $90.1(16.8)$ & 33 & & $96.5(16.2)$ & -6.4 & $(-12.8$ to .1$)$ & .05 \\
\hline \multicolumn{10}{|l|}{ Early language milestones } \\
\hline One word 1 year (no) & 30 & 25.6 & & 2 & 7.4 & & 18.3 & $(.8$ to 28.4$)$ & .04 \\
\hline Two words 2 year (no) & 37 & 32.7 & & 1 & 3.7 & & 29.0 & (12.4 to 38.6$)$ & .003 \\
\hline $\begin{array}{l}\text { Language impaired }(\mathrm{GCC}<55) \\
\text { CCC }-2 \text { composite scores }\end{array}$ & 117 & 81.8 & & 27 & 79.4 & & 2.4 & $(-10.1$ to 19.5$)$ & .77 \\
\hline $\begin{array}{l}\text { GCC } \\
\text { (sum scales A-H) }\end{array}$ & 143 & & $38.2(18.4)$ & 34 & & $42.9(15.7)$ & -4.7 & $(-11.4$ to 2.1$)$ & .17 \\
\hline $\begin{array}{l}\text { Structural Language Score } \\
\text { (sum scales A-D) }\end{array}$ & 143 & & $21.4(10.5)$ & 34 & & $24.7(9.0)$ & -3.3 & $(-7.2$ to .6$)$ & .09 \\
\hline $\begin{array}{l}\text { General Pragmatics Score } \\
\text { (sum scales E-H) }\end{array}$ & 143 & & $16.8(10.0)$ & 34 & & 18.2 & -1.3 & $(-5.0$ to 2.3$)$ & .47 \\
\hline
\end{tabular}

Data are expressed as $n(\%)$ or mean (SD). The denominator for the reported proportions in this table excludes those with missing data. IQ was obtained from various age-appropriate standardized tests

$A S D$ autism spectrum disorder, $N D D$ neurodevelopmental disorder 
Fig. 3 Clustered error bar mean of CCC-2 subscale scores in the total study sample $(N=177)$, by sex. Means and $95 \% \mathrm{CI}$

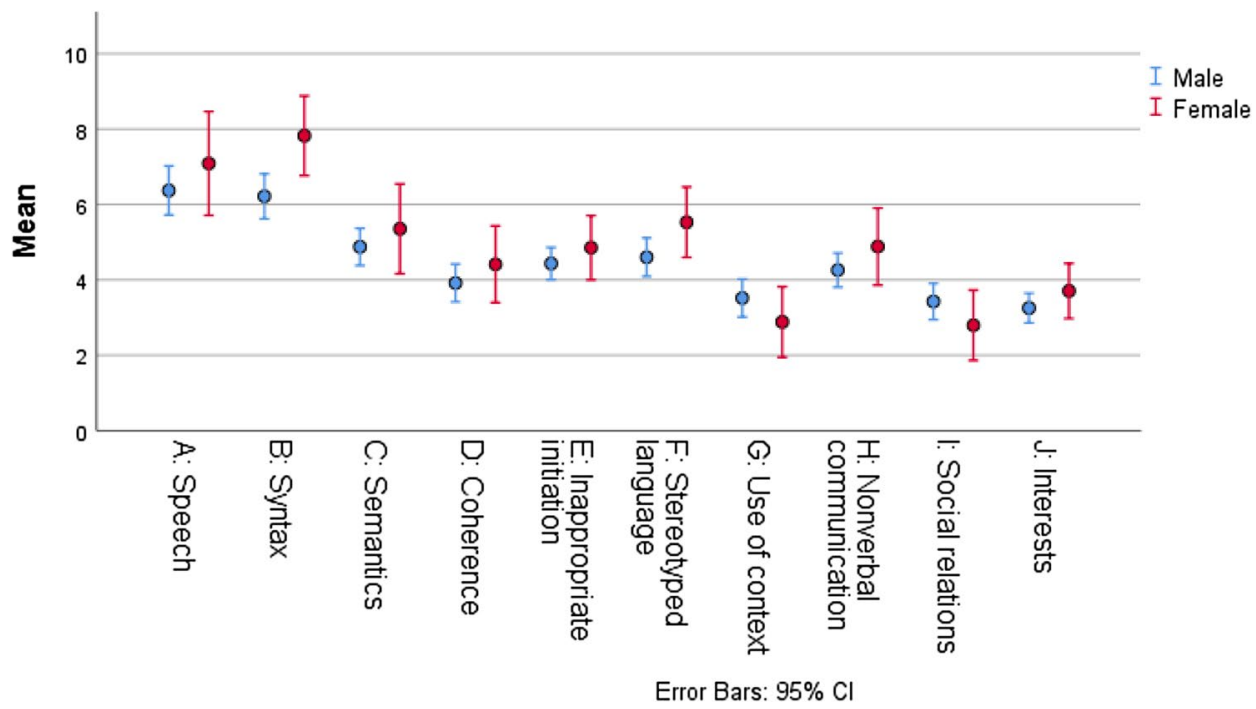

the General Pragmatics Score. Females, however, performed better than males on measures of verbal IQ $(96.5(S D=16.2)$ versus $90.1(S D=16.8)$, respectively, $p=.05)$. Only one female $(1 / 27,4 \%)$ was reported with language delay compared with males $(37 / 113,33 \%), p=.003$.

\section{Discussion}

In this study of language characteristics in a sample of children evaluated for ASD by specialist health services we found that the majority had language impairment, i.e. general communication skills below the CCC-2 cut-off $(\mathrm{GCC}<55)$. Structural language deficits were common and strongly associated with pragmatic competence across the whole sample. Pragmatic language impairments were most profound in children with ASD. Early language delay was more common among males and associated with structural language deficits, whereas pragmatic language and social skills did not differ significantly among children with and without language delay. Our findings support that pragmatic language impairment as a dimensional symptom profile probably reflect a confluence of risk factors, among them structural language deficits. Further, they support that early language delay is associated with later language abilities that are distinct from autistic symptoms. Lastly, we contribute to recent reports that females with ASD may be recognized and diagnosed later than males probably due to stronger verbal skills and a reduced rate of early language delay.

\section{Structural and Pragmatic Language Deficits Across the Range of Autistic Symptoms}

Existing research on language impairment often overlooks differences in autism severity (Levinson et al. 2020). As a result, little is known about how distinct language skills may present differently across the autism spectrum. In the present study, we applied a dimensional approach and studied language skills in a sample of children evaluated for ASD, with and without ASD diagnoses. We found a large extent of language impairment across the whole sample, as measured by the CCC-2 $(\mathrm{GCC}<55)$, that did not differ significantly between children diagnosed with ASD (84\%) and children not fulfilling the diagnostic criteria (non-ASD; 69\%). The observed extent of language impairment is comparable to previous findings among children with Asperger syndrome and children with ADHD (Helland et al. 2012), both of which were common diagnoses in the present sample.

Although both structural and pragmatic language skills were widely distributed across both groups, pragmatic aspects (the use) of language were most affected. This is in line with previous results among school-aged children with ASD (Geurts and Embrechts 2008; Boucher 2012). As expected, the ASD and non-ASD group differed significantly on the subscales that map social deficits characteristic of ASD ('social relations' and 'interests', $p=.004$ and $p=.001$, respectively). Although our non-ASD group was small $(n=29)$, significant pragmatic deficits were found compared to Norwegian norms, albeit less profound than in the ASD group. These results support the concept of pragmatic language impairment as a dimensional symptom profile present across a range of NDDs, with ASD "at the extreme end", as suggested by Norbury (2014, p. 212). Pragmatic skills include a child's ability to initiate and maintain a mutual conversation, to flexibly adapt the use of language to the social context and resolve ambiguities, as well as nonverbal aspects of communication. Our findings coincide with previous studies using the CCC-2 that have reported more profound pragmatic impairments among children with ASD compared to typically developing children (e.g. Geurts and 
Embrechts 2008; Oi et al. 2017; Helland et al. 2012), but also compared to children with other NDDs, such as specific language impairment (Oi et al. 2017; Geurts and Embrechts 2008; Norbury et al. 2004), and ADHD (Geurts and Embrechts 2008; Kuijper et al. 2017; Helland et al. 2012). With the exception of Oi et al. (2017) who investigated whether aspects of communicative impairment were continuously distributed in a population-based sample, these studies compared categorically defined clinical groups, which were also considerably smaller than the ASD group in the present sample. Applying a dimensional approach, we extend their findings to a larger clinical population of children with autistic symptoms.

Together, the CCC-2 structural scales ('speech', 'syntax', 'semantics', 'coherence') assess language functions apart from pragmatics that are commonly affected in children with specific language impairment (Norbury et al. 2004), including vocabulary and articulatory issues. By combining these subscales, we were able to assess structural aspects of the child's language, as assessed by their caregivers. This includes the ability to apply rules for producing and combining speech sounds and combinations of words to form phrases and sentences, as well as the ability to understand and use the meaning of words and sentences, and to use a coherent language. We found that structural language deficits are common (compared to Norwegian norms) in children evaluated for suspected ASD, with deficits in 'syntax' being relatively infrequent, and 'coherence' being the most affected subscale. The overall extent and profile of structural language deficits did not differ between children with and without an ASD diagnosis, and is consistent with the language profile reported from previous studies in school-aged children with ASD, as reviewed by Boucher (2012). Further, the observed extent of deficits is comparable to previous studies in school-aged children with ASD (Helland et al. 2012; Kuijper et al. 2017; Baixauli-Fortea et al. 2019). Clinicians and researchers have long been aware of the high comorbidity between ASD and other NDDs (Lord et al. 2018), as well as their potential impact on specific aspects of language and communication. Still, studies on language skills in ASD rarely provide information on these comorbid diagnoses (Levinson et al. 2020). In the present study the proportion of children diagnosed with (co-occurrent) ADHD was high in both the ASD and the non-ASD group. Our finding that structural language skills were equally impaired in both groups are consistent with previous reports that children with ASD and ADHD are not possible to distinguish from each other on CCC-2 structural scales, while on pragmatic scales they can (Kuijper et al. 2017; Geurts and Embrechts 2008; Helland et al. 2012).

Co-occurring language impairment may influence the presentation of ASD symptoms, as well as the functional impairment of the child. Therefore, assessment of language skills is recommended as part of the diagnostic evaluation for ASD (Hyman et al. 2020). In line with Kjelgaard and Tager-Flusberg (2001) we report considerable heterogeneity in the language skills of children with ASD, but a somewhat smaller proportion of children with no language impairment. In our sample, only 16\% (24/148) of children with ASD had no language impairment (GCC $>55)$. Suren et al. (2019a) reviewed patients records obtained from the specialist health service for 503 children with ASD in Norway, finding that the assessments largely were conducted in accordance with local guidelines. Notably, however, only a minority of children in their study underwent a formal assessment of language as part of their clinical evaluation (33\%). Although the present sample consist of children who underwent an assessment using the CCC-2, our findings underscore that structural language deficits are frequent across the range of autistic symptoms and important to assess also in verbal children evaluated for ASD.

\section{High Correlation Between Current Structural and Pragmatic Language Skills}

Previous work that has examined the relationship between specific language domains and other aspects of functioning has largely focused on the association between pragmatic language and social skills deficits in ASD. The expression of pragmatic competence often relies on verbal skills. As such, the close relationship between structural and pragmatic language skills observed in the present sample is expected, and consistent with previous reports of an association between structural and pragmatic language skills in children with specific language impairment (Ketelaars et al. 2009) as well as children with ASD (Volden et al. 2009; Baixauli-Fortea et al. 2019; Levinson et al. 2020). We replicate and extend their findings to a large group of children with a broad range of autistic symptoms. By investigating this relationship in a broader clinical population, we found that structural and pragmatic language skills, as measured by the CCC-2, were highly correlated regardless of diagnostic group. This suggests that the close relationship between structural and pragmatic language skills is present not only in children with ASD, but also in children with autistic symptoms seen across various NDDs. Further, our finding that pragmatic competence was statistically not solely explained by structural language skills is compatible with the notion that pragmatic language impairments might reflect a confluence of risk factors, among them deficits in structural language (Norbury 2014). Volden et al. (2009) not only reported structural language skills to predict performance on a standardized measure of pragmatic language in youth with ASD, but also that pragmatic language in turn uniquely predicted social skills. Taken together, these and the present findings suggest that although mediated by pragmatic language, structural 
language skills may influence social skills, and demonstrate the necessity of examining language skill domains separately when evaluating children with suspected ASD.

Notably, both composites used in the present analyses include various aspects of structural and pragmatic skills. The Structural Language Score include both form ('speech' and 'syntax') and content ('semantics' and 'coherence') skills, that may also tap into vocabulary knowledge and discourse. Although a strong correlation was found, it is likely that some aspects of structural language bear a stronger significance on pragmatic competence than others. Further, some aspects of pragmatic competence may be stronger related to structural language than others. In a CCC-2 validation study, Norbury et al. (2004) reported no group differences between children with specific language impairment and groups thought to have more severe pragmatic difficulties on the 'stereotyped language' and 'use of context' subscales, suggesting that structural language difficulties may influence ratings on these subscales. For instance, a child with limited expressive skills may rely on a few phrases that might appear stereotyped. Moreover, children with specific language impairment demonstrated strengths in 'nonverbal communication', suggesting that their structural deficits did not impact this aspect of pragmatic competence (Norbury et al. 2004).

The profile of language impairments in children with ASD is reported to change with pragmatic impairments becoming more prominent relative to structural deficits by school-age (Rapin and Dunn 2003; Geurts and Embrechts 2008). Such changes may be related to maturity, interventions, the interplay of developmental risk factors to cause more profound impairments over time (Geurts and Embrechts 2008), as well the pervasiveness of pragmatic language impairment becoming more apparent with increasing demands. The present sample mainly comprised school-aged children, and the cross-sectional design does not allow conclusions regarding language trajectories. Importantly, however, we report structural language deficits to be common in school-age children evaluated for suspected ASD, and to be strongly associated with pragmatic competence across the range of autistic symptoms.

\section{Early Language Delay and Current Language and Social Impairment}

Deficits in pragmatic language and social communication may not become fully manifest until demands exceed limited capacity (Baird and Norbury 2016). As young children with clear developmental disabilities are likely to be referred earlier for specialist assessment than those without, it has been cautioned against overlooking young children with ASD and no language delay (Lord et al. 2018). As expected in a sample of verbal children, the proportion of children with language delay in the present study was relatively low, but comparable to findings from the Norwegian MoBa cohort (Suren et al. 2019b). While children with language delay had more structural language deficits compared to children without language delay, they did not differ in pragmatic language and social skills. In an earlier study Kenworthy et al. (2012) reported age of first phrases among verbal children with ASD to predict later structural language, but not other social communicative impairments characteristic of ASD. Moreover Loucas et al. (2008) found phrase speech to be acquired significantly later in ASD children with cooccurrent language impairment compared to those without, while current autistic symptoms and pragmatic language impairment did not differ. Although caution when interpreting retrospectively reported language milestone data is recommended (Hus et al. 2011; Ozonoff et al. 2018), these and the present findings suggest that early language delay represents an important predictor of later language ability that is distinct from autism symptoms. Further, they lend support to the recent revisions of the Diagnostic and Statistical Manual of Mental Disorders (DSM-5) and the International classification of diseases (ICD-11), where delayed or impaired language is no longer included as a core symptom of ASD, but should be specified as co-occurrent language impairment (American Psychiatric Association 2013; World Health Organization 2018).

\section{Sex-Based Differences in Language Profile}

Assessing male and female language profiles separately may contribute to a better understanding of the female ASD phenotype. Consistent with findings in clinically-referred children with ASD (Solomon et al. 2012) we found no significant sex differences on the CCC- 2 composite scores. We did, however, find that females presented with a relative strength in their structural language skills, performing better than males on the 'syntax' subscale. Consistent with our results, a recent review by Lai and Szatmari (2020) suggest that females with ASD may show higher linguistic abilities, mirroring normative sex differences and placing them closer to typically developing peers and away from males with ASD. However, these linguistic strengths may mask their real struggles with social communication, and complicate or delay the detection of their ASD symptoms (ParishMorris et al. 2017; Lai and Szatmari 2020). The presence of early language delay has been related to earlier diagnosis of ASD (Goodwin et al. 2017; Lord et al. 2018). Early language delay was rare among females in the present sample, whose mean age at ASD diagnosis was higher compared with males. Although our findings may not seem surprising, they contrast with several studies that did not find significant sex differences in language and communication among ASD individuals (Tillmann et al. 2018; Solomon et al. 2012; 
Lawson et al. 2018). Due to the limited number of female participants in our study $(n=34)$, it is not possible to draw firm conclusions on potential sex differences. However, two large studies recently reported that children with ASD and more advanced language abilities, particularly females, were diagnosed later than non-verbal and minimally verbal children (McCormick et al. 2020; Salomone et al. 2016).

\section{Strengths and Limitations}

A major strength of our study is the dimensional approach which enabled us to study language skills in a sample of children assessed for ASD with and without ASD diagnoses, increasing generalizability to the broader population of children evaluated for ASD. The large sample size compared to previous studies of CCC-2 in children with ASD, including a relatively large number of females, is another strength. Further, available data on age at inclusion and cognitive abilities allowed adjustment for these potential confounding factors.

Limitations include a potential selection bias, as referral for assessment in the present sample was based on concern. The participants may not be representative for children with autistic symptoms in the general population. Further, we relied upon parent report of structural and pragmatic language skills in everyday contexts as measured by the Norwegian version of the CCC-2. As this checklist is only suitable for verbal children who speak Norwegian, our results may be less applicable to younger children, children with no verbal language, as well as other languages. A small number of children with a history of hearing impairment were not excluded, as they were considered verbal and had completed the CCC-2. We used retrospective parent report on early language delay collected at inclusion (age from 4 to 18 years), introducing the possibility of recall bias. This information, however, was supplementary to available information in the child's medical record. Although the precision of information regarding attainment of phrase speech at 2 years' age may have varied, we do not consider it likely to have biased our results systematically. Further, the proportion of children with early language delay observed in the present study is comparable to a previous Norwegian study by Suren et al. (2019b). Mild or moderate deficits in social and communicative competence may be missed in the context of cooccurring difficulties, such as ADHD (Skuse et al. 2009), a common NDD in the present sample. As the proportion of individuals diagnosed with ADHD did not differ between the two diagnostic groups, we do not consider their inclusion to have biased our results in one direction. The large proportion with co-occurring ADHD, however, may have contributed to the observed late age at ASD diagnosis (11.5 years). Finally, the use of clinical diagnoses obtained from different clinics is a potential source of bias. Misclassification in both directions for ASD and the non-ASD disorders are considered possible, but not very probable. A recent review of patient records show that $95 \%$ of ASD diagnoses provided a high standard of documentation within the Norwegian specialist health service and meet the diagnostic criteria (Suren et al. 2019a).

\section{Clinical Implications}

Language and communication skills are critical to the cognitive and social development of children, and highly predictive of academic and employment outcomes, regardless of the primary diagnosis (Norbury and Paul 2018; ContiRamsden and Durkin 2015). Children evaluated for suspected ASD commonly present with structural as well as pragmatic language impairments, that are likely to persist and to require on-going support as the child gets older. These impairments represent an important target of intervention. In a clinical setting, such interventions should be centered on the child's age and profile of strength and needs, rather than the diagnostic category alone. They should be multifaceted, incorporating techniques for improving structural language skills, social communication and interaction, as well as using linguistic context to improve comprehension (Norbury 2014). Our results suggest that both language milestones and the CCC-2 may be helpful for identifying children with increased risk for structural language impairments, which needs to be managed separately from the presenting ASD symptoms.

\section{Conclusion}

We found a large extent of structural as well as pragmatic language deficits in children evaluated for suspected ASD. Structural language deficits were associated with reduced pragmatic competence across the whole sample and more common among children with early language delay, while pragmatic language impairments were most profound in children with diagnosed ASD. Our results support the notion of pragmatic language impairment as a dimensional symptom profile potentially linked to several developmental risk factors, among them structural language deficits. This underscores the importance of including language skills assessment in the diagnostic evaluation of children with suspected ASD. Applied both in clinical and research settings language milestones have the potential for identifying a subgroup of children with increased risk for structural language impairments. These children may benefit from specific language interventions in addition to management of the core ASD symptoms. 


\section{Appendix}

\section{Supplementary Material and Sensitivity Analyses}

For the purpose of comparison with previous samples we have included information on participant characteristics by ASD group status (Table 5). The Norwegian CCC-2 manual (Bishop 2011, p. 72) provides a description on how to assess the internal consistency of the parents' answers. In cases of invalid consistency check, it is recommended not to interpret the individuals' test result. In the present sample, we compared participant characteristics between individuals with valid consistency check on the CCC-2 $(n=153)$ and $n=22$ individuals with invalid CCC-2 scores not passing the instruments' consistency check (Table 6). Participant characteristics did not differ substantially between these two groups, except that a larger proportion of children not passing the consistency check were diagnosed with two or more neurodevelopmental disorders $(p=.007)$. Children with invalid consistency check, however, had lower scores on the General Communication and Structural Language composites, indicating larger impairment in general communication and structural language skills. Further, the group with invalid consistency check also had lower pragmatic scores, that were more proportionate to their structural language skills. In the present study, analyses with and without exclusion of individuals with invalid consistency check did not affect the main outcomes substantially. The proportion of parents $(n=22 / 175 ; 12.6 \%)$ that were inconsistent in their answers on the CCC-2 in the present study is in line with findings by Geurts and Embrechts (2008) (9.3-22.8\%), and most likely due to the change in questions types throughout the CCC-2. During the first part of the CCC-2 questions focusing on difficulties are negatively formulated, whereas the last 20 questions focusing on strengths are positively formulated. Although instructions clearly state that there is a change in question type, answers to the last questions may be given as if they were still negatively formulated. Consequently, the scaled scores of each subscale will be higher (indicating less difficulties) than if the questions were answered consistently, underestimating the difficulties a child encounter. Considering results on the consistency check is important when using the CCC-2 in individual assessment of the communication pattern of a child in a clinical setting, where an invalid consistency check should elicit careful consideration of possible reasons for the invalid result. However, our results indicate that not passing the reliability check may not be a random event, and that exclusion of these individuals may bias results on a group level and underestimate the true extent of structural language deficits in research samples.

In order to assess the potential impact of including children with intellectual disability $(n=8)$ on CCC-2 composite scores in the present study, as well as estimates of group differences and associations between structural and pragmatic language skills, we checked whether these children represented outliers in the distribution of CCC-2 scores (Fig. 4). Further, main analyses were repeated with these individuals excluded, resulting in a modest attenuation of the results, not affecting the statistical significance of our findings.

In the present study we have chosen to present scaled scores from the CCC-2 as recommended in the CCC-2 manual. Further, we have chosen to use the Structural Language and the General Pragmatics composite scores, although not described in the manual. No Norwegian norms are available for these composite scores. However, since 10 is the average of the scaled scores on each of the four subscales for both indexes, a putative mean value of 40 is expected for each. Previous studies reporting these composites have presented their results as raw totals (Kuijper et al. 2017; Baixauli-Fortea et al. 2019), while we have chosen to report scaled scores. We therefore present some of our results as CCC-2 raw scores for comparison (Fig. 5 and Table 7). Kuijper et al. (2017) reported a mean (SD) Structural Language Score in the ASD group of 20.4 (9.0), and a mean (SD) General Pragmatic Score of 37.4 (13.1), both of which are higher (indicating larger deficits) compared with the present sample. In a more recent study, Baixauli-Fortea et al. (2019) report a mean (SD) Structural Language Score in the ASD group of 19.0 (9.4), which is close to the observed value in the present sample. There are, however, important differences between these two and the present study; smaller sample sizes $(n=36$ and $n=52$ ), the inclusion of only participants with normal range cognitive abilities, as well as a more limited age range under study (6-12 and 7-11 years), which may limit comparability. 
Table 5 Participant characteristics by diagnostic group $(N=177)$

\begin{tabular}{|c|c|c|c|c|c|c|}
\hline & \multicolumn{3}{|c|}{$\operatorname{ASD}(n=148)$} & \multicolumn{3}{|c|}{ Non-ASD $(n=29)$} \\
\hline & $n$ & $(\%)$ & Mean (SD) & $n$ & $(\%)$ & Mean (SD) \\
\hline Male sex & 119 & 80.4 & & 24 & 82.8 & \\
\hline Age (years) at inclusion & 148 & & $12.5(3.2)$ & 29 & & $11.0(3.7)$ \\
\hline Age (years) at ASD diagnosis & 144 & & $11.5(3.3)$ & & & \\
\hline \multicolumn{7}{|l|}{ Autistic symptom severity } \\
\hline ADI-R nonverbal total & 66 & & $22.2(9.5)$ & 10 & & $10.0(10.6)$ \\
\hline SCQ total & 94 & & $15.8(7.5)$ & 20 & & $10.3(8.2)$ \\
\hline SRS raw total & 136 & & $86.7(27.7)$ & 26 & & $66.2(34.8)$ \\
\hline Age (years) at cognitive testing & 142 & & $10.0(3.3)$ & 26 & & $10.0(3.7)$ \\
\hline Nonverbal IQ & 137 & & $102.7(18.4)$ & 24 & & $101.6(19.0)$ \\
\hline Verbal IQ & 138 & & $90.8(17.0)$ & 25 & & $94.8(15.9)$ \\
\hline \multicolumn{7}{|l|}{ Early language milestones } \\
\hline One word 1 year (no) & 30 & 24.0 & & 2 & 10.5 & \\
\hline Two words 2 year (no) & 31 & 25.6 & & 7 & 36.8 & \\
\hline \multicolumn{7}{|l|}{ Diagnoses } \\
\hline Intellectual disability (F70-79) & 7 & 4.8 & & 1 & 3.4 & \\
\hline ADHD (F90) & 86 & 59.3 & & 17 & 63.0 & \\
\hline Communication disorder (F80) & 5 & 3.4 & & 2 & 7.4 & \\
\hline Specific learning disorder $(\mathrm{F} 81+\mathrm{F} 83)$ & 12 & 8.3 & & 6 & 22.2 & \\
\hline Motor disorders (F82 + F95) & 22 & 15.2 & & 5 & 18.5 & \\
\hline Epilepsy & 8 & 5.4 & & 2 & 6.9 & \\
\hline Cerebral palsy & 1 & 0.7 & & 1 & 3.6 & \\
\hline Other NDD (F94) & 1 & 0.7 & & 0 & 0 & \\
\hline Motor disorders (F82 + F95) & 22 & 15.2 & & 5 & 18.5 & \\
\hline Epilepsy & 8 & 5.4 & & 2 & 6.9 & \\
\hline Cerebral Palsy & 1 & 0.7 & & 1 & 3.6 & \\
\hline Other NDD (F94) & 1 & 0.7 & & 0 & 0 & \\
\hline \multicolumn{7}{|l|}{ No of NDDs } \\
\hline 0 & 0 & & & 5 & 19.2 & \\
\hline 1 & 47 & 32.9 & & 11 & 42.3 & \\
\hline$\geq 2$ & 96 & 67.1 & & 10 & 38.5 & \\
\hline Prematurity (yes) & 19 & 14.3 & & 7 & 25.9 & \\
\hline Paternal age (years) & 97 & & $32.3(5.9)$ & 21 & & $33.2(6.3)$ \\
\hline Maternal age (years) & 106 & & $29.8(5.2)$ & 25 & & $29.4(5.3)$ \\
\hline \multicolumn{7}{|l|}{ Ethnicity } \\
\hline European (Caucasian) & 129 & 89.0 & & 28 & 100.0 & \\
\hline
\end{tabular}

Data are expressed as $n(\%)$ or mean (SD). The denominator for the reported proportions in this table excludes those with missing data. IQ was obtained from various age-appropriate standardized tests

$A D I-R$ Autism Diagnostic Interview-Revised, ASD autism spectrum disorder, SCQ Social Communication Questionnaire, SRS Social Responsiveness Scale, NDD neurodevelopmental disorder 
Table 6 Participant characteristics by CCC-2 consistency check $(n=175)$

\begin{tabular}{|c|c|c|c|c|c|c|}
\hline & \multicolumn{3}{|c|}{ Valid $(n=153)$} & \multicolumn{3}{|c|}{ Not valid $(n=22)$} \\
\hline & $n$ & $(\%)$ & Mean (SD) & $n$ & $(\%)$ & Mean (SD) \\
\hline Male sex & 123 & 80.4 & & 18 & 81.8 & \\
\hline ASD & 127 & 83.0 & & 20 & 90.9 & \\
\hline Age (years) at inclusion & 153 & & $12.3(3.4)$ & 22 & & $12.3(2.7)$ \\
\hline Age (years) at ASD diagnosis & 123 & & $11.4(3.4)$ & 20 & & $11.6(2.7)$ \\
\hline Nonverbal IQ & 138 & & $102.8(18.8)$ & 21 & & $100.2(15.3)$ \\
\hline \multicolumn{7}{|l|}{ No of NDDs } \\
\hline 0 & 4 & 2.7 & & 0 & 0 & \\
\hline 1 & 56 & 38.1 & & 2 & 10.0 & \\
\hline$\geq 2$ & 87 & 59.2 & & 18 & 90.0 & \\
\hline \multicolumn{7}{|l|}{ Early language development } \\
\hline One word 1 year (no) & 26 & 21.0 & & 6 & 31.6 & \\
\hline Two words 2 year (no) & 33 & 27.5 & & 5 & 26.3 & \\
\hline \multicolumn{7}{|l|}{ CCC-2 composite scores } \\
\hline $\begin{array}{l}\text { GCC } \\
\text { (sum scales A-H) }\end{array}$ & 153 & & $40.2(18.3)$ & 22 & & $30.0(9.8)$ \\
\hline $\begin{array}{l}\text { Structural Language Score } \\
\text { (sum scales A-D) }\end{array}$ & 153 & & $22.7(10.4)$ & 22 & & $15.6(6.3)$ \\
\hline $\begin{array}{l}\text { General Pragmatics Score } \\
\text { (sum scales E-H) }\end{array}$ & 153 & & $17.5(10.1)$ & 22 & & $14.3(4.9)$ \\
\hline \multicolumn{7}{|l|}{ Ethnicity } \\
\hline European (Caucasian) & 135 & 90.0 & & 21 & 95.5 & \\
\hline
\end{tabular}

Data are expressed as $n(\%)$ or mean (SD). The denominator for the reported proportions in this table excludes those with missing data. IQ was obtained from various age-appropriate standardized tests. 2 participants had missing information on results of the consistency check

$A S D$ autism spectrum disorder, $C C C$-2 Children's Communication Checklist Second Edition, NDD neurodevelopmental disorder

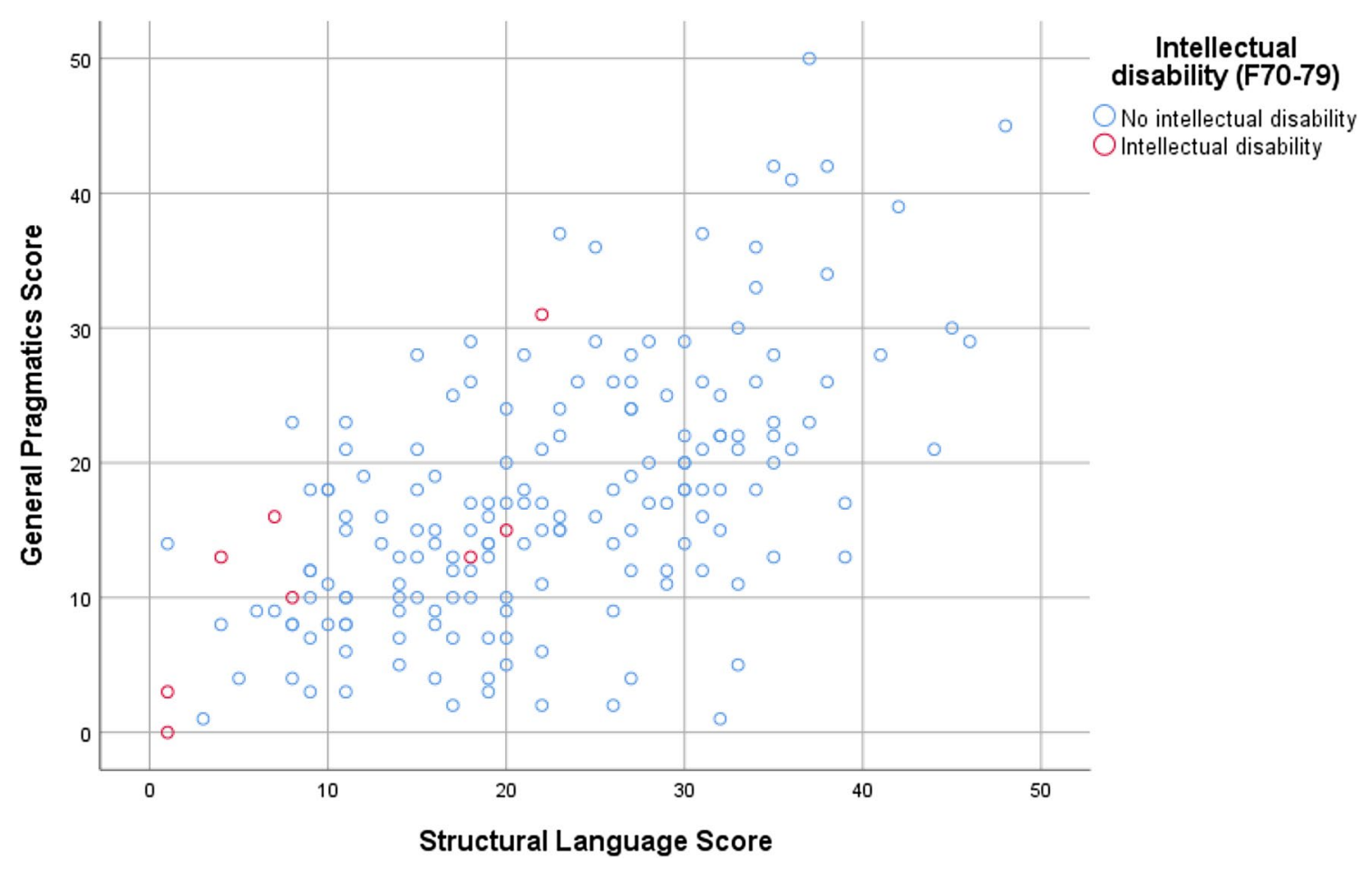

Fig. 4 Distribution of Structural Language and General Pragmatics composite scores, in the group with $(n=8)$ and without $(n=169)$ co-occurrent intellectual disability 


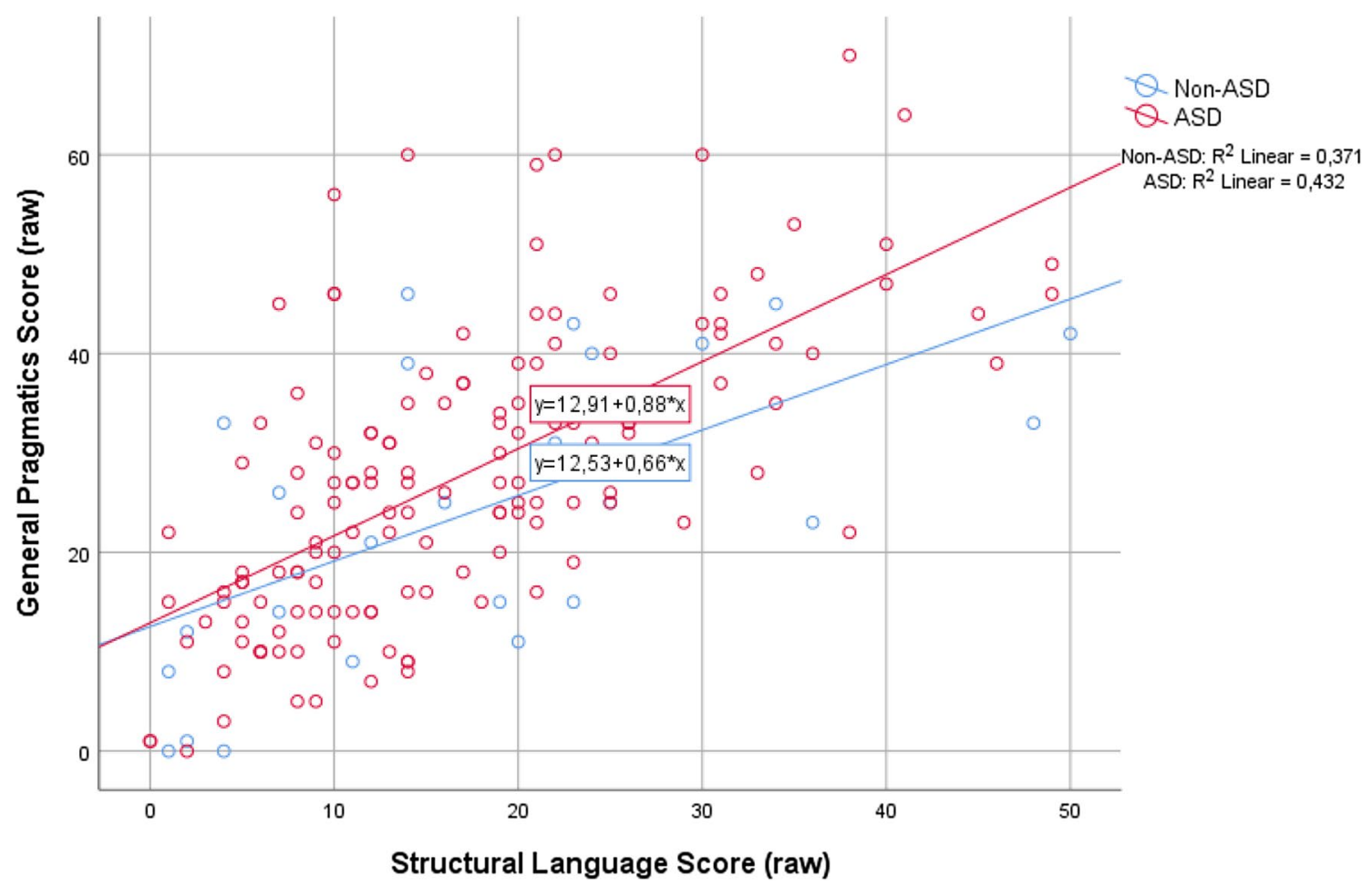

Fig. 5 Distribution of Structural Language and General Pragmatics composite scores (raw scores) across the study sample, and their linear associations in the group with and without diagnosed autism spectrum disorder (ASD; $n=147$ and non-ASD; $n=28$ )

Table 7 CCC-2 raw scores (a low score indicates better language ability): means, standard deviations, and comparisons between diagnostic groups

\begin{tabular}{|c|c|c|c|c|c|c|c|}
\hline & \multicolumn{4}{|c|}{ Groups } & \multicolumn{3}{|c|}{ Difference } \\
\hline & \multirow{2}{*}{\multicolumn{2}{|c|}{$\frac{\mathrm{ASD}}{n=147}$}} & \multirow{2}{*}{\multicolumn{2}{|c|}{$\frac{\text { Non-ASD }}{n=28}$}} & \multirow[b]{3}{*}{ Estimate } & \multirow[b]{3}{*}{$95 \% \mathrm{CI}$} & \multirow[b]{3}{*}{$p$} \\
\hline & & & & & & & \\
\hline & Mean & $\mathrm{SD}$ & Mean & SD & & & \\
\hline \multicolumn{8}{|l|}{ CCC-2 subscale scores } \\
\hline A. Speech & 2.4 & 3.2 & 3.5 & 4.1 & -1.2 & $(-2.5$ to .2$)$ & .09 \\
\hline B. Syntax & 2.3 & 2.7 & 2.8 & 3.1 & -.5 & $(-1.6$ to .6$)$ & .36 \\
\hline C. Semantics & 5.7 & 3.4 & 5.5 & 4.4 & .1 & $(-1.3$ to 1.6$)$ & .85 \\
\hline D. Coherence & 6.8 & 4.3 & 6.6 & 4.1 & .2 & $(-1.5$ to 2.0$)$ & .79 \\
\hline E. Inappropriate initiation & 8.5 & 4.6 & 8.3 & 5.4 & .3 & $(-1.7$ to 2.2$)$ & .79 \\
\hline F. Stereotyped language & 4.4 & 3.4 & 3.6 & 3.0 & .8 & $(-.6$ to 2.1$)$ & .28 \\
\hline G. Use of context & 7.3 & 4.4 & 6.9 & 4.3 & .4 & $(-1.3$ to 2.2$)$ & .63 \\
\hline H. Nonverbal communication & 7.7 & 4.5 & 5.9 & 4.0 & 1.8 & $(.9$ to -.005$)$ & .05 \\
\hline I. Social relations & 7.6 & 4.0 & 5.7 & 4.2 & 2.0 & (.3 to 3.6$)$ & .02 \\
\hline J. Interests & 9.6 & 4.6 & 7.3 & 3.8 & 2.3 & $(.5$ to 4.1$)$ & .01 \\
\hline \multicolumn{8}{|l|}{ CCC-2 composite scores } \\
\hline $\begin{array}{l}\text { Structural Language Score (sum scales } \\
\text { A-D) }\end{array}$ & 17.1 & 10.7 & 18.4 & 13.2 & -1.3 & $(-5.9$ to 3.2$)$ & .57 \\
\hline General Pragmatics Score (sum scales E-H) & 27.9 & 14.3 & 24.7 & 14.3 & 3.2 & $(-2.6$ to 9.1$)$ & .28 \\
\hline
\end{tabular}

$A S D$ autism spectrum disorder, $C C C$-2 Children's Communication Checklist Second Edition, $S D=$ standard deviation, $C I$ confidence interval, $p p$-value for independent samples t-test 
Acknowledgements We are grateful to all the children and parents who participated in the research, as well as the clinicians and researchers in the BUPgen network who assisted in the collection and preparation of data included herein.

Author Contributions LR and TN conceptualized and designed the study, conducted the initial analyses, drafted the initial manuscript, and reviewed and revised the manuscript. AMS, BW, and OAA contributed in conceptualizing and designing the study, interpreted the findings and critically reviewed the manuscript and its analyses. SL reviewed the analyses and reviewed and revised parts of the manuscript. All authors approved the final manuscript as submitted and are accountable for all aspects of the work.

Funding Open Access funding provided by NTNU Norwegian University of Science and Technology (incl St. Olavs Hospital - Trondheim University Hospital). The BUPgen Study group is part of the research network NeuroDevelop. The BUPgen project is supported by the National Research Council of Norway (Grant \#213694), and the South-Eastern Norway Regional Health Authority funds the Regional Research Network NeuroDevelop (Grant\#2015086). The corresponding author holds a PhD grant from Møre og Romsdal Hospital Trust.

\section{Compliance with Ethical Standards}

Conflict of interest AMS and OAA declares no direct conflict of interest related to this article. AMS discloses that she received travel support for conference attendance from Medice in 2018. OAA discloses that he has received speaker's honorarium from Lundbeck. All other authors declare that they have no conflicts of interest.

Ethical Approval The BUPgen study was approved by the Norwegian Regional Committee for Medical and Health Research Ethics South East (REK\#2012/1967) and the Norwegian Data Inspectorate and performed in accordance with the ethical standards as laid down in the 1964 Declaration of Helsinki and its later amendments.

Informed Consent Informed consent was obtained from all individual participants (and/or parents when necessary due to age) included in the study.

Open Access This article is licensed under a Creative Commons Attribution 4.0 International License, which permits use, sharing, adaptation, distribution and reproduction in any medium or format, as long as you give appropriate credit to the original author(s) and the source, provide a link to the Creative Commons licence, and indicate if changes were made. The images or other third party material in this article are included in the article's Creative Commons licence, unless indicated otherwise in a credit line to the material. If material is not included in the article's Creative Commons licence and your intended use is not permitted by statutory regulation or exceeds the permitted use, you will need to obtain permission directly from the copyright holder. To view a copy of this licence, visit http://creativecommons.org/licenses/by/4.0/.

\section{References}

American Psychiatric Association. (2013). Diagnostic and statistical manual of mental disorders (DSM-5) (5th ed.). Washington DC: American Psychiatric Association.

Ash, A. C., Redmond, S. M., Timler, G. R., \& Kean, J. (2017). The influence of scale structure and sex on parental reports of children's social (pragmatic) communication symptoms.
Clinical Linguistics \& Phonetics, 31(4), 293-312. https://doi. org/10.1080/02699206.2016.1257655.

Baird, G., \& Norbury, C. F. (2016). Social (pragmatic) communication disorders and autism spectrum disorder. Archives of Disease in Childhood, 101(8), 745-751. https://doi.org/10.1136/archdischi ld-2014-306944.

Baixauli-Fortea, I., Miranda Casas, A., Berenguer-Forner, C., ColomerDiago, C., \& Rosello-Miranda, B. (2019). Pragmatic competence of children with autism spectrum disorder: Impact of theory of mind, verbal working memory, ADHD symptoms, and structural language. Appl Neuropsychol Child, 8(2), 101-112. https://doi. org/10.1080/21622965.2017.1392861.

Bishop, D. V. (1998). Development of the Children's Communication Checklist (CCC): A method for assessing qualitative aspects of communicative impairment in children. Journal of Child Psychology and Psychiatry and Allied Disciplines, 39(6), 879-891.

Bishop, D. V. M. (2000). Pragmatic language impairment: A correlate of SLI, a distinct subgroup, or part of the autistic continuum? In D. V. M. Bishop \& L. B. Leonard (Eds.), Speech and language impairments in children: Causes, characteristics, intervention and outcome (pp. 99-113). Hove: Psychology Press.

Bishop, D. V. M. (2003). The children's communication checklist. London: Harcourt Assessment.

Bishop, D. V. M. (2011). The Children's communication checklist (2edn., Norwegian version). Stockholm: Pearson Assessment.

Bishop, D. V., \& Norbury, C. F. (2002). Exploring the borderlands of autistic disorder and specific language impairment: A study using standardised diagnostic instruments. Journal of Child Psychology and Psychiatry and Allied Disciplines, 43(7), 917-929.

Bornstein, M. H., Hahn, C. S., Putnick, D. L., \& Pearson, R. M. (2018). Stability of core language skill from infancy to adolescence in typical and atypical development. Science Advances, 4(11), 7422. https://doi.org/10.1126/sciadv.aat7422.

Boucher, J. (2012). Research review: Structural language in autistic spectrum disorder-characteristics and causes. Journal of Child Psychology and Psychiatry and Allied Disciplines, 53(3), 219233. https://doi.org/10.1111/j.1469-7610.2011.02508.x.

Cohen, N. J., Barwick, M. A., Horodezky, N. B., Vallance, D. D., \& Im, N. (1998). Language, achievement, and cognitive processing in psychiatrically disturbed children with previously identified and unsuspected language impairments. Journal of Child Psychology and Psychiatry and Allied Disciplines, 39(6), 865-877.

Constantino, J. N., Davis, S. A., Todd, R. D., Schindler, M. K., Gross, M. M., Brophy, S. L., et al. (2003). Validation of a brief quantitative measure of autistic traits: Comparison of the social responsiveness scale with the autism diagnostic interview-revised. Journal of Autism and Developmental Disorders, 33(4), 427-433.

Constantino, J., \& Gruber, C. (2005). Social responsive scale (SRS) manual. Los Angeles, CA: Western Psychological Services.

Constantino, J. N., \& Todd, R. D. (2003). Autistic traits in the general population: A twin study. Archives of General Psychiatry, 60(5), 524-530. https://doi.org/10.1001/archpsyc.60.5.524.

Constantino, J. N., \& Todd, R. D. (2005). Intergenerational transmission of subthreshold autistic traits in the general population. Biological Psychiatry, 57(6), 655-660. https://doi.org/10.1016/j. biopsych.2004.12.014.

Conti-Ramsden, G., \& Durkin, K. (2015). What factors influence language impairment considering resilience as well as risk. Folia Phoniatrica et Logopaedica, 67(6), 293-299.

Fagerland, M. W., Lydersen, S., \& Laake, P. (2015). Recommended confidence intervals for two independent binomial proportions. Statistical Methods in Medical Research, 24(2), 224-254. https ://doi.org/10.1177/0962280211415469.

Geurts, H. M., \& Embrechts, M. (2008). Language profiles in ASD, SLI, and ADHD. Journal of Autism and Developmental Disorders, 38(10), 1931-1943. https://doi.org/10.1007/s10803-008-0587-1. 
Geurts, H. M., Hartman, C., Verte, S., Oosterlaan, J., Roeyers, H., \& Sergeant, J. A. (2009). Pragmatics fragmented: The factor structure of the Dutch children's communication checklist (CCC). International Journal of Language and Communication Disorders, 44(5), 549-574. https://doi.org/10.1080/136828208022433 44.

Gilmour, J., Hill, B., Place, M., \& Skuse, D. H. (2004). Social communication deficits in conduct disorder: A clinical and community survey. Journal of Child Psychology and Psychiatry and Allied Disciplines, 45(5), 967-978. https://doi. org/10.1111/j.1469-7610.2004.t01-1-00289.x.

Goodwin, A., Matthews, N. L., \& Smith, C. J. (2017). The Effects of early language on age at diagnosis and functioning at school age in children with autism spectrum disorder. Journal of Autism and Developmental Disorders, 47(7), 2176-2188. https://doi. org/10.1007/s10803-017-3133-1.

Green, R. M., Travers, A. M., Howe, Y., \& McDougle, C. J. (2019). Women and autism spectrum disorder: Diagnosis and implications for treatment of adolescents and adults. Current Psychiatry Reports, 21(4), 22. https://doi.org/10.1007/s11920-019-1006-3.

Happé, F., \& Frith, U. (2020). Annual Research Review: Looking back to look forward-changes in the concept of autism and implications for future research. Journal of Child Psychology and Psychiatry and Allied Disciplines, 61(3), 218-232. https://doi.org/10.1111/ jcpp.13176.

Helland, W. A., Biringer, E., Helland, T., \& Heimann, M. (2009). The usability of a Norwegian adaptation of the Children's Communication Checklist Second Edition (CCC-2) in differentiating between language impaired and non-language impaired 6- to 12-year-olds. Scandinavian Journal of Psychology, 50(3), 287292. https://doi.org/10.1111/j.1467-9450.2009.00718.x.

Helland, W. A., Biringer, E., Helland, T., \& Heimann, M. (2012). Exploring language profiles for children with ADHD and children with asperger syndrome. J Atten Disord, 16(1), 34-43. https://doi. org/10.1177/1087054710378233.

Hollund-Møllerhaug, L. (2010). Forekomst av språkvansker hos norske barn. Tidsskrift for Norsk Psykologforening, 47, 608-610.

Hus, V., Taylor, A., \& Lord, C. (2011). Telescoping of caregiver report on the Autism Diagnostic Interview-Revised. Journal of Child Psychology and Psychiatry and Allied Disciplines, 52(7), 753760. https://doi.org/10.1111/j.1469-7610.2011.02398.x.

Hyman, S. L., Levy, S. E., \& Myers, S. M. (2020). Identification, evaluation, and management of children with autism spectrum disorder. Pediatrics. https://doi.org/10.1542/peds.2019-3447.

Kenworthy, L., Wallace, G. L., Powell, K., Anselmo, C., Martin, A., \& Black, D. O. (2012). Early language milestones predict later language, but not autism symptoms in higher functioning children with autism spectrum disorders. Research in Autism Spectrum Disorders, 6(3), 1194-1202.

Ketelaars, M. P., Cuperus, J., Jansonius, K., \& Verhoeven, L. (2010). Pragmatic language impairment and associated behavioural problems. International Journal of Language and Communication Disorders, 45(2), 204-214. https://doi.org/10.3109/1368282090 2863090.

Ketelaars, M. P., Cuperus, J. M., van Daal, J., Jansonius, K., \& Verhoeven, L. (2009). Screening for pragmatic language impairment: The potential of the children's communication checklist. Research in Developmental Disabilities, 30(5), 952-960. https:// doi.org/10.1016/j.ridd.2009.01.006

Kjelgaard, M. M., \& Tager-Flusberg, H. (2001). An investigation of language impairment in autism: Implications for genetic subgroups. Language and Cognitive Processes, 16(2-3), 287-308. https://doi.org/10.1080/01690960042000058.

Kreiser, N. L., \& White, S. W. (2014). ASD in females: Are we overstating the gender difference in diagnosis? Clinical Child and
Family Psychology Review, 17(1), 67-84. https://doi.org/10.1007/ s10567-013-0148-9.

Kuijper, S. J., Hartman, C. A., Bogaerds-Hazenberg, S. T., \& Hendriks, P. (2017). Narrative production in children with autism spectrum disorder (ASD) and children with attention-deficit/hyperactivity disorder (ADHD): Similarities and differences. Journal of Abnormal Psychology, 126(1), 63-75. https://doi.org/10.1037/ abn0000231.

La Valle, C., Plesa-Skwerer, D., \& Tager-Flusberg, H. (2020). Comparing the pragmatic speech profiles of minimally verbal and verbally fluent individuals with autism spectrum disorder. Journal of Autism and Developmental Disorders, 50(10), 3699-3713. https ://doi.org/10.1007/s10803-020-04421-7.

Lai, M. C., \& Szatmari, P. (2020). Sex and gender impacts on the behavioural presentation and recognition of autism. Current Psychiatry Reports, 33(2), 117-123. https://doi.org/10.1097/ yco.0000000000000575.

Lawson, L. P., Joshi, R., Barbaro, J., \& Dissanayake, C. (2018). Gender differences during toddlerhood in autism spectrum disorder: A prospective community-based longitudinal follow-up study. Journal of Autism and Developmental Disorders, 48(8), 2619-2628. https://doi.org/10.1007/s10803-018-3516-y.

Levinson, S., Eisenhower, A., Bush, H. H., Carter, A. S., \& Blacher, J. (2020). Brief report: Predicting social skills from semantic, syntactic, and pragmatic language among young children with autism spectrum disorder. Journal of Autism and Developmental Disorders, 50(11), 4165-4175. https://doi.org/10.1007/s1080 3-020-04445-z.

Levy, S. E., Giarelli, E., Lee, L. C., Schieve, L. A., Kirby, R. S., Cunniff, C., et al. (2010). Autism spectrum disorder and cooccurring developmental, psychiatric, and medical conditions among children in multiple populations of the United States. Journal of Developmental and Behavioral Pediatrics, 31(4), 267-275. https://doi.org/10.1097/DBP.0b013e3181d5d03b.

Lord, C., Elsabbagh, M., Baird, G., \& Veenstra-Vanderweele, J. (2018). Autism spectrum disorder. Lancet, 392(10146), 508520. https://doi.org/10.1016/s0140-6736(18)31129-2.

Lord, C., Rutter, M., DiLavore, P. S., \& Risi, S. (1999). Autism diagnostic observation schedule (ADOS). Los Angeles, CA: Western Psychological Services.

Loucas, T., Charman, T., Pickles, A., Simonoff, E., Chandler, S., Meldrum, D., et al. (2008). Autistic symptomatology and language ability in autism spectrum disorder and specific language impairment. Journal of Child Psychology and Psychiatry and Allied Disciplines, 49(11), 1184-1192. https://doi.org/10.111 1/j.1469-7610.2008.01951.x.

Lydersen, S., Langaas, M., \& Bakke, Ø. (2012). The exact unconditional z-pooled test for equality of two binomial probabilities: Optimal choice of the Berger and Boos confidence coefficient. Journal of Statistical Computation and Simulation, 82(9), 1311-1316.

McCormick, C. E. B., Kavanaugh, B. C., Sipsock, D., Righi, G., Oberman, L. M., Moreno De Luca, D., et al. (2020). Autism heterogeneity in a densely sampled U.S. population: Results from the first 1000 participants in the RI-CART study. Autism Research, 13(3), 474-488. https://doi.org/10.1002/aur.2261.

Moreno-De-Luca, A., Myers, S. M., Challman, T. D., Moreno-DeLuca, D., Evans, D. W., \& Ledbetter, D. H. (2013). Developmental brain dysfunction: Revival and expansion of old concepts based on new genetic evidence. Lancet Neurology, 12(4), 406-414. https://doi.org/10.1016/s1474-4422(13)70011-5.

Norbury, C. F. (2014). Practitioner review: Social (pragmatic) communication disorder conceptualization, evidence and clinical implications. Journal of Child Psychology and Psychiatry and Allied Disciplines, 55(3), 204-216. https://doi.org/10.1111/ jcpp.12154. 
Norbury, C. F., Nash, M., Baird, G., \& Bishop, D. (2004). Using a parental checklist to identify diagnostic groups in children with communication impairment: A validation of the Children's Communication Checklist-2. International Journal of Language and Communication Disorders, 39(3), 345-364. https://doi. org/10.1080/13682820410001654883.

Norbury, C. F., \& Paul, R. (2018). Disorders of speech, language, and communication. In A. Thapar, D. S. Pine, S. Scott, M. J. Snowling, \& E. A. Taylor (Eds.), Rutter's child and adolescent psychiatry (6th ed., pp. 683-701). New York: Wiley.

Oi, M., Fujino, H., Tsukidate, N., Kamio, Y., Yoshimura, Y., Kikuchi, M., et al. (2017). Quantitative aspects of communicative impairment ascertained in a large national survey of Japanese children. Journal of Autism and Developmental Disorders, 47(10), 30403048. https://doi.org/10.1007/s10803-017-3226-x.

Ozonoff, S., Li, D., Deprey, L., Hanzel, E. P., \& Iosif, A. M. (2018). Reliability of parent recall of symptom onset and timing in autism spectrum disorder. Autism, 22(7), 891-896. https://doi. org/10.1177/1362361317710798.

Parish-Morris, J., Liberman, M. Y., Cieri, C., Herrington, J. D., Yerys, B. E., Bateman, L., et al. (2017). Linguistic camouflage in girls with autism spectrum disorder. Molecular Autism, 8, 48. https:// doi.org/10.1186/s13229-017-0164-6.

Posserud, M. B., Lundervold, A. J., \& Gillberg, C. (2006). Autistic features in a total population of 7-9-year-old children assessed by the ASSQ (Autism Spectrum Screening Questionnaire). Journal of Child Psychology and Psychiatry and Allied Disciplines, 47(2), 167-175. https://doi.org/10.1111/j.1469-7610.2005.01462.x.

Rapin, I., \& Dunn, M. (2003). Update on the language disorders of individuals on the autistic spectrum. Brain and Development, 25(3), 166-172. https://doi.org/10.1016/s0387-7604(02)00191-2.

Rutter, M., Bailey, A., \& Lord, C. (2003a). The social communication questionnaire. Los Angeles, CA: Western Psychological Services.

Rutter, M., Le Couteur, A., \& Lord, C. (2003b). Autism diagnostic interview-revised. Los Angeles, CA: Western Psychological Services.

Salomone, E., Charman, T., McConachie, H., \& Warreyn, P. (2016). Child's verbal ability and gender are associated with age at diagnosis in a sample of young children with ASD in Europe. Child, 42(1), 141-145. https://doi.org/10.1111/cch.12261.

Skuse, D. H., Mandy, W., Steer, C., Miller, L. L., Goodman, R., Lawrence, K., et al. (2009). Social communication competence and functional adaptation in a general population of children: preliminary evidence for sex-by-verbal IQ differential risk. Journal of the American Academy of Child and Adolescent Psychiatry, 48(2), 128-137. https://doi.org/10.1097/CHI.0b013e31819176b8.

Solomon, M., Miller, M., Taylor, S. L., Hinshaw, S. P., \& Carter, C. S. (2012). Autism symptoms and internalizing psychopathology in girls and boys with autism spectrum disorders. Journal of Autism and Developmental Disorders, 42(1), 48-59. https://doi. org/10.1007/s10803-011-1215-z.
Suren, P., Havdahl, A., Oyen, A. S., Schjolberg, S., Reichborn-Kjennerud, T., Magnus, P., et al. (2019a). Diagnosing autism spectrum disorder among children in Norway. Tidsskrift for den Norske Laegeforening. https://doi.org/10.4045/tidsskr.18.0960.

Suren, P., Saasen-Havdahl, A., Bresnahan, M., Hirtz, D., Hornig, M., Lord, C., et al. (2019b). Sensitivity and specificity of early screening for autism. BJPsych Open, 5(3), e41. https://doi.org/10.1192/ bjo.2019.34.

Tager-Flusberg, H. (2016). Risk factors associated with Language in autism spectrum disorder: Clues to underlying mechanisms. Journal of Speech, Language, and Hearing Research, 59(1), 143-154. https://doi.org/10.1044/2015_jslhr-1-15-0146.

Tillmann, J., Ashwood, K., Absoud, M., Bolte, S., Bonnet-Brilhault, F., Buitelaar, J. K., et al. (2018). Evaluating sex and age differences in ADI-R and ADOS scores in a large European multi-site sample of individuals with autism spectrum disorder. Journal of Autism and Developmental Disorders, 48(7), 2490-2505. https:// doi.org/10.1007/s10803-018-3510-4.

Van Wijngaarden-Cremers, P. J., van Eeten, E., Groen, W. B., Van Deurzen, P. A., Oosterling, I. J., \& Van der Gaag, R. J. (2014). Gender and age differences in the core triad of impairments in autism spectrum disorders: A systematic review and meta-analysis. Journal of Autism and Developmental Disorders, 44(3), 627-635. https://doi.org/10.1007/s10803-013-1913-9.

Volden, J., Coolican, J., Garon, N., White, J., \& Bryson, S. (2009). Brief report: pragmatic language in autism spectrum disorder: Relationships to measures of ability and disability. Journal of Autism and Developmental Disorders, 39(2), 388-393. https:// doi.org/10.1007/s10803-008-0618-y.

Wechsler, D. (1999). Wechsler abbreviated scale of intelligence. San Antonio, TX: The Psychological Corporation.

Wechsler, D. (2003). Wechsler intelligence scale for children-fourth edition (WISC-IV). San Antonio, TX: The Psychological Corporation.

Wechsler, D. (2008). Wechsler adult intelligence scale-fourth edition (WAIS-IV). San Antonio, TX: The Psychological Corporation.

Wechsler, D. (2012). Wechsler preschool and primary scale of intelligence-fourth edition. San Antonio, TX: The Psychological Corporation.

World Health Organization. (1992). The ICD-10 classification of mental and behavioural disorders: Clinical descriptions and diagnostic guidelines. Geneva: World Health Organization.

World Health Organization. (2018). International classification of diseases for mortality and morbidity statistics (11th Revision). Retrieved from https://icd.who.int/browse11/1-m/en.

Publisher's Note Springer Nature remains neutral with regard to jurisdictional claims in published maps and institutional affiliations. 